\title{
Paediatric COVID-19 case with regard to the family infection chain and the psychosocial context
}

\author{
Silke Schwarz ${ }^{1}$, Hanno Krafft ${ }^{1}$, Christian Steuber $^{2}$, Katja Boehm ${ }^{1}$, and David Martin ${ }^{1}$ \\ ${ }^{1}$ Universität Witten/Herdecke \\ ${ }^{2}$ Affiliation not available
}

June 22, 2020

\begin{abstract}
The biological father of an 11-year-old girl infects his daughter, who returns to her biological mother's family before the father's diagnosis. The daughter endures a 1-day, mild illness. However, despite close physical contact prior to and during the girl's illness, her mother, stepfather and 1-year-old half-brother were not infected.
\end{abstract}

Paediatric COVID-19 case with regard to the family infection chain and the psychosocial context

Silke Schwarz ${ }^{\mathrm{a}}$, Dr. med., Christian Steuber ${ }^{\mathrm{b}}$, Hanno Krafft ${ }^{\mathrm{a}}$, MSc.,Katja Boehm ${ }^{\mathrm{a}}$, Dr. phil., David Martin $^{\mathrm{a}, \mathrm{c}}$, Prof. Dr. med.

${ }^{a}$ Witten / Herdecke University, Chair of Medical Theory, Integrative and Anthroposophical Medicine, Germany;

${ }^{\mathrm{b}}$ ARCHE, Practice for children and young people, Germany

${ }^{\mathrm{c}}$ Tübingen University, Department of Paediatrics, Germany

Correspondence address Dr. med. Silke Schwarz, University of Witten/Herdecke, Chair of Medical Theory, Integrative and Anthroposophical Medicine, Alfred-Herrhausen-Strasse 50, 58448 Witten. Email: Silke.Schwarz@uni-wh.de

Short title: Pediatric COVID-19 infection

Keywords: corona, pediatrics, infection chain, stigmatisation, case report, COVID-19, SARS-CoV-2, quarantine

Key Clinical Message: Despite close physical contact SARS-CoV-2 transmission by children does not have to be assumed in principle within a family.

Source of funding: No funding was requested for this case report.

Financial disclosure: The authors have no financial ties relevant to this article.

Conflict of interest: The authors have no conflicts of interest.

Abbreviations: SARS-CoV-2 (severe acute respiratory syndrome coronavirus 2); COVID-19 (Corona Virus Disease 2019)

Note: All names in this case report have been changed by the authors. "Melina", her mother, father and stepfather have read the manuscript and approved of its publication 


\section{Contributors' Statement Page}

Dr. med. Silke Schwarz, Christian Steuber, MSc. Hanno Krafft, Dr. phil. Katja Boehm and Prof. Dr. med. David Martin conceptualized and designed the case report, drafted the initial manuscript, and critically reviewed and revised the manuscript. All authors approved the final manuscript as submitted and agree to be accountable for all aspects of the work

\section{Abstract}

The biological father of an 11-year-old girl infects his daughter, who returns to her biological mother's family before the father's diagnosis. The daughter endures a 1-day, mild illness. However, despite close physical contact prior to and during the girl's illness, her mother, stepfather and 1-year-old half-brother were not infected.

\section{Background}

In Germany the first SARS-CoV-2infection was confirmed on January $28^{\text {th }}, 2020$. A recent showed that less than $1 \%$ of cases occurred in children under 10 years of age ${ }^{1}$. It appears that children are as likely to be infected as adults, but the course of infection is more likely to be asymptomatic or mild ${ }^{3}$. We report on one of the first infected children in Germany with 8-week follow-up to the index infection and discuss biological and psychosocial aspects.

\section{Methods}

"Melina" an 11-year old girl infected with SARS-CoV-2 was prospectively followed up by her family doctor and interviews were conducted by a researcher physician. Family members were also semi-qualitatively interviewed, including clinical manifestations, epidemiological characteristics, and laboratory tests. Nasooropharyngeal swab tests were used to detect SARS-CoV-2 via real-time PCR cobas, Roche Company. In addition to the COVID-19 pathogen (SARS-CoV-2), this test detects SARS- CoV-1 and other sarbecoviruses. No cross reactivity with common respiratory corona viruses (CoV-NL63, 229E, HKU, OC43 or MERS-CoV). Melina drew a picture of herself in the corona situation. Six weeks after Melina's positive initial testing, her pediatrician carried out serum antibody tests in the family using the Acro 2019-nCoV IgG/IgM Rapid Test. IgG relative sensitivity: $100 \%$ (95\% Confidence Interval (CI): $86.0 \%-100 \%$ ), relative specificity: $98.0 \%$ (95\% CI: $89.4 \%-99.9 \%$ ); IgM relative sensitivity: $85.0 \%$ (95\% CI: 62.1\%-96.8\%), relative Specificity: $96.0 \%$ (95\% CI: $86.3 \%-99.5 \%)$.

\section{Case presentation with regard to the corona infection}

After a business trip within Germany from February $19^{\text {th }}-21^{\text {st }}, 2020$, where he had a conference and meals with an Italian man who later was tested positive for COVID-19, Melina's biological father developed first mild symptoms (fatigue) on February $23^{\text {rd }}$. Melina, whose parents live separately, visited her father from February $22^{\text {nd }}$ and returned to her mother in the evening of February $24^{\text {th }}$, on which Melina's father developed significant fatigue, fever, headache, aching limbs and cough.

On February $25^{\text {th }}$, the father was informed of the Italian's positive test and, due to his symptoms, was referred to a university hospital on February $26^{\text {th }}$ where he was also tested for SARS-CoV-2. Three other attendees of the meeting, were also positive. After the positive result was communicated on February $27^{\text {th }}$, Melina's father remained in quarantine at the university hospital until March $4^{\text {th }}$.

Melina developed her first symptoms on March $1^{\text {st }}$ : "dizzyness" with a slight headache. She quickly developed an elevated body temperature of $38.1^{\circ} \mathrm{C}$ and was given a $400 \mathrm{mg}$ ibuprofen tablet by her mother. By the next morning Melina had no more symptoms. The mother reported: "It came as if by magic and disappeared just as quickly." The following symptoms from our COVID-19 symptom list were denied: cough, rhinitis, irritability, fatigue, tearfulness, abdominal pain, vomiting, diarrhoea, sore throat, aching limbs, disorders of the sense of smell or taste, loss of appetite, sensitivity to light, pressure on the chest, scratching of the throat.

On March $2^{\text {nd }}$, Melina, her half-brother, her mother and her stepfather were also tested. On the same day, 
Melina's mother had diarrhea and a febrile feeling at a temperature of $37.6{ }^{\circ} \mathrm{C}$. On March $3^{\text {rd }}$, the family received the results that Melina was tested positive for SARS-CoV-2, but her mother, brother and stepfather were negative. On March $4^{\text {th }}$, Melina returned to her father, who was allowed to leave the hospital. Melina was tested negative for SARS-CoV-2 on March $6^{\text {th }}$ and $9^{\text {th }}$, the day Melina returned to her mother's family.

From March $3^{\text {rd }}$, Melina and her mother's family remained in quarantine for 2 weeks without further symptoms. Antibody tests on April $13^{\text {th }}$ on Melina, her mother, her stepfather and half-brother showed IgG-positive results only for Melina (Figure $\mathbf{1}$ and $\mathbf{2}$ ).

\section{Melina's medical history}

Melina was born in November 2009 after an uncomplicated pregnancy. She was an uncomplicated baby, was breastfed and was in day care from the age of one. She is fully vaccinated according to STIKO. As a small child she had frequent middle ear infections. Surgical operations, accidents or allergies are denied. In connection with flu-like infections, she occasionally had a fever of up to $39.8^{\circ} \mathrm{C}$. Since starting school Melina has migraine attacks about 4 times per year with aura, vomiting and severe headaches. The mother sees a connection to both distress and eustress. The migraine is treated with ibuprofen and Melina usually returns to school on the next day.

\section{Current family situation}

The 42-year-old mother works as a technician, the 41-year-old biological father works as product manager. Melina's parents separated when she was 4 years old. It was a difficult time for Melina and she slept in her mother's bed again for about a year. Two years ago, the mother married a 39 years old product manager. The patchwork family lives in a rented apartment; Melina has her own room there. All three adults are German citizens; Melina's father of Turkish origin. All adults do not smoke, drink alcohol only occasionally and do not take vitamins. German high school graduation is their highest educational level. Melina's mother and stepfather are in friendly contact with Melina's biological father, who lives $6 \mathrm{~km}$ away. Melina sees him weekly, stays overnight with him in her own room and likes to be there. Visits take place in flexible arrangement. Melina attends the 5th grade of a grammar school, is an eager student, does sports every week, plays an instrument and has her own PC, which she uses daily. She is a popular child, invited by friends and praised by teachers. The mother describes Melina as very likeable, positive and sensitive, and says she often has to stand back because of her little half-brother. The mother compensates for this by spending a lot of time with her in the evening. The family has no pets. No particular health, family or work pressures are mentioned.

\section{Time of quarantine}

The mother describes the quarantine as a "terrible" experience. After Melina's positive test result, i.e. the day after her symptoms, the recommended personal distance inside the family was adhered to. Melina ate in her room with her mother as company at a distance and different bathrooms were used. "We cuddle a lot," said the mother, "especially in the evening, which did not happen for the 2.5 days until she went to her daddy. This put a lot of strain on Melina and she kept saying that she would like to hug or cuddle us. That was the worst part of the whole thing for her, not the illness itself." Despite this difficult experience Melina drew quite positive picture in retrospect on April $13^{\text {th }}$ (figure 3 ). The family did not leave the house for 1.5 weeks and ordered food online. For fear that Melina could be avoided, the infection was not communicated to the school, nor with friends or neighbours.

Discussion Although Melina was quickly infected by her father, the infection did not spread, despite very close, hugging and kissing physical contact even at the time of the acute illness when a large amount of virus exchange must be assumed ${ }^{2}$. Melina also did not infect her 1-year-old half-brother, even though babies do get infected with COVID-19 ${ }^{3}$. Data differ on whether children are less susceptible to Sars-CoV-2 infection ${ }^{4}$. Our case fits with the findings of a $15 \%$ within-household secondary infection rate ${ }^{5}$. Should it be shown that children are less likely to infect others, this could be of relevance for the health policy debate.

Subfebrile temperatures, headache and dizziness can be added to the symptom canon ${ }^{6}$. The short course of 
the disease fits with the described initial disease dynamics ${ }^{7}$, with $41.5 \%$ of children having fever at any time of the disease ${ }^{8,9}$. There were no problems associated with the use of ibuprofen.

The case suggests that fear of social stigmatisation can lead to not disclosing the infection to acquaintances or to important institutions. It can be assumed that the number of infected people is higher than generally assumed.

\section{References}

1. Lu X, Zhang L, Du H, et al. SARS-CoV-2 Infection in Children. $N$ Engl $J$ Med . Published online March 18, 2020. doi:10.1056/NEJMc2005073

2. Aaby P. Patterns of exposure and severity of measles infection. Copenhagen 1915-1925. Ann Epidemiol . 1992;2(3):257-262. doi:10.1016/1047-2797(92)90058-x

3. Wei M, Yuan J, Liu Y, Fu T, Yu X, Zhang Z-J. Novel Coronavirus Infection in Hospitalized Infants Under 1 Year of Age in China.JAMA . Published online February 14, 2020. doi:10.1001/jama.2020.2131

4. Lee P-I, Hu Y-L, Chen P-Y, Huang Y-C, Hsueh P-R. Are children less susceptible to COVID-19? J Microbiol Immunol Infect . Published online February 25, 2020. doi:10.1016/j.jmii.2020.02.011

5. Bi Q, Wu Y, Mei S, et al. Epidemiology and Transmission of COVID-19 in Shenzhen China: Analysis of 391 cases and 1,286 of their close contacts. medRxiv . Published online January 1, 2020:2020.03.03.20028423. doi:10.1101/2020.03.03.20028423

6. Ji L-N, Chao S, Wang Y-J, et al. Clinical features of pediatric patients with COVID-19: a report of two family cluster cases. World J Pediatr . Published online March 16, 2020:1-4. doi:10.1007/s12519-020-00356-2

7. Dong Y, Mo X, Hu Y, et al. Epidemiological Characteristics of 2143 Pediatric Patients With 2019 Coronavirus Disease in China.Pediatrics . Published online March 16, 2020:e20200702. doi:10.1542/peds.2020-0702

8. Y W, L X, N Z, X L. Retracted: A novel DNA sensor based on C60NPs-PAMAM-PtPNPs to detect VKORC1 gene for guiding rational clinical therapy with Warfarin. Anal Chim Acta . 2019;1078:232. doi:10.1016/j.aca.2019.07.037

9. Zhu L, Wang J, Huang R, et al. Clinical characteristics of a case series of children with coronavirus disease 2019. Pediatr Pulmonol . doi:10.1002/ppul.24767

Figure 1: Immunological tests

Figure 2: Antibody Test for Sars-CoV-2 antibodies at 6 weeks Follow-up: (from left to right) Melina's stepfather, her mother, Melina, and her brother. Melina: IgM negative, IgG positive; all others IgM and IgG negative.

Figure 3: Melina's drawing shows the distance she had to keep to her mother during the Corona quarantine. The thumbs up show she had only subfebrile temperatures and did not find the illness so bad. 
Immunological Tests:

02/26/2020 Biological father SARS-CoV-2 PCR: positive

03/02/2020 Melina SARS-CoV-2 PCR*: positive

03/03/2020 Mother SARS-CoV-2 PCR*: negative

03/06/2020 Melina SARS-CoV-2 PCR* : negative

03/09/2020 Melina SARS-CoV-2 PCR*: negative

04/13/2020 Follow-up serum antibody rapid Test** in serum by the pediatrician: Melina's half-brother, mother and stepfather: $\operatorname{IgM}$ and $\mathrm{IgG}$ negative. Melina IgM negative, IgG positive

Other: Blood group: mother is 0 Rhesus positive; not known for other family members

Tests: $\quad$ *RT-PCR cobas SARS-CoV-2

**Acro 2019-nCoV IgG/IgM, Rapid Test

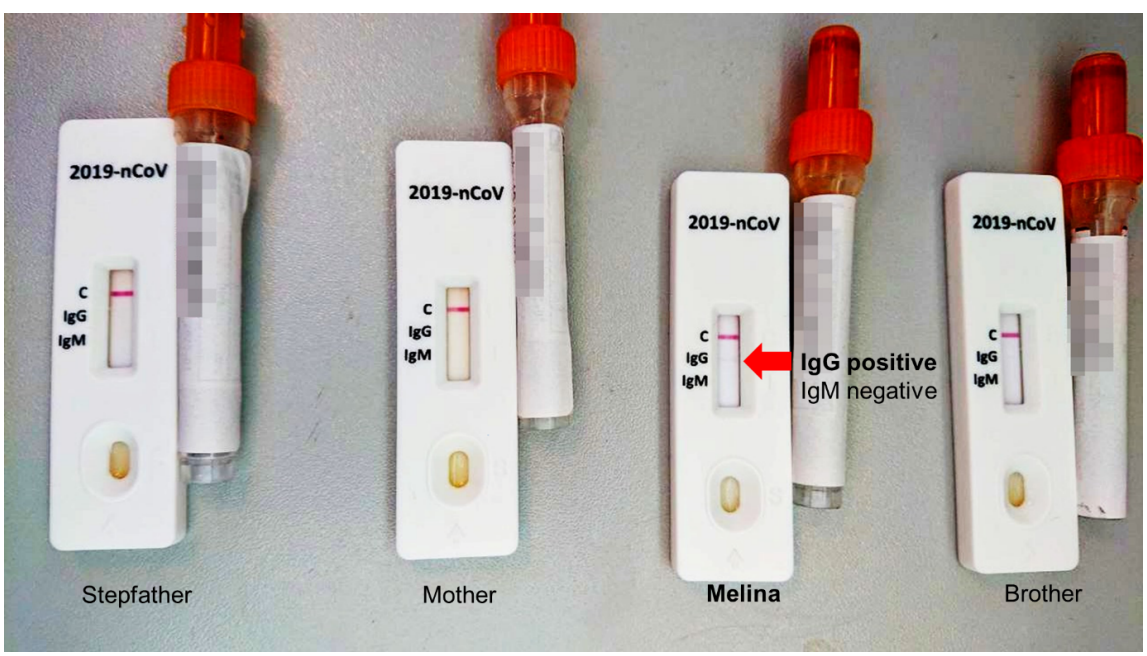




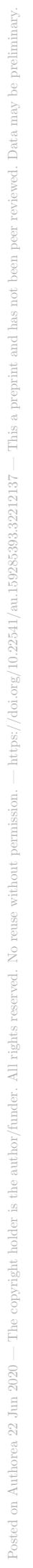

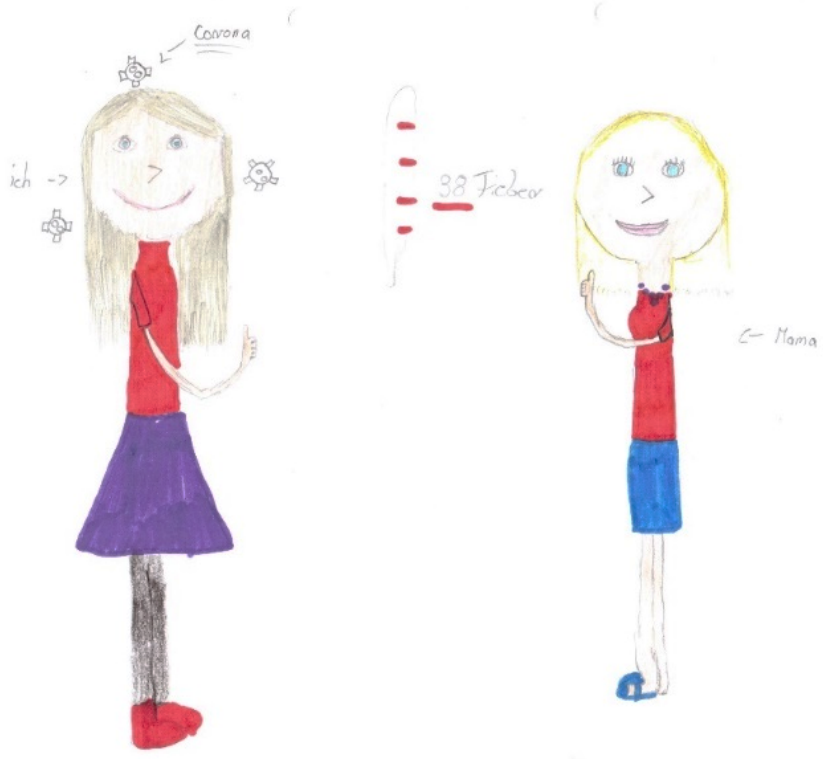

6 